\title{
EFL and ESP Learners' Use of Language Learning Strategies: A Study of Collocations
}

\author{
Omid Tabatabaei \\ Department of English, Najafabad Branch, Islamic Azad University, Najafabad, Iran \\ Hourieh-Sadat Hoseini \\ Department of English, Najafabad Branch, Islamic Azad University, Najafabad, Iran
}

\begin{abstract}
The present study was intended to explore language learning strategies used by Iranian EFL and ESP learners when dealing with collocations in reading passages. Additionally, the survey was aimed to explore differences between strategy use by EFL and ESP participants who were 182 EFL and 146 ESP learners from three universities in Isfahan, namely Islamic Azad University-Najafabad Branch, Islamic Azad University-Khorasgan Branch, and University of Isfahan. Oxford's (1990) Strategy Inventory for Language Learning (SILL) was used, which is a fifty-item questionnaire and participants were required to use a scale of 1 to 5 for each statement. To find the types of language learning strategies, the results were subjected to Principal Component Analysis (PCA). The PCA for both EFL and ESP participants revealed the presence of five components or factors. These factors included Metacognitive, Socio-Affective, Cognitive-Compensatory, Cognitive-Memory, and Memory-Social for EFL participants and Cognitive, Compensatory-Social, Metacognitive Memory, Cognitive-Metacognitive, and Cognitive-Affective for ESP participants. As the results indicate, EFL and ESP participants used quite different strategies. In fact, in contrast to EFL participants who preferred Social strategies, those in the ESP group resorted to Cognitive strategies. In addition, ESP participants did not seem to benefit from Affective, Social, and Memory strategies the way EFL participants did.
\end{abstract}

Index Terms - language learning strategies, collocations, SILL, reading, EFL, ESP

\section{INTRODUCTION}

Cognitive psychological studies have shown learners are actively involved while they are learning a second or foreign language. Since the mid-1970s such studies have shown that successful language learners develop certain learning strategies (Rubin, 1975). Numerous studies have shown the substantial efficacy of learning language strategies among EFL learners with different first language backgrounds (e.g., Hsu \& Huang 2004; O'Malley \& Chamot, 1990; Oxford, 1990). One such study is Mayer (1996) who explored vocabulary acquisition by English learners and concluded that learners using more learning strategies are more responsible for learning and more proficient. Another study conducted by Lawson and Hogben (1996) showed that learners who utilize more learning strategies had better performance than other learners on learning vocabulary.

Oxford (1990) outlined a host of learning and communication strategies that have been successful among learners. Her taxonomy includes direct and indirect strategies, which are classified as six categories; for example, metacognitive ones which direct EFL learners to make necessary adaptations to their own learning. regulate their learning. The other categories consist of Affective strategies, the ones related to emotions and affects, social strategies, the ones related to requirements necessary to interact with the language of the target community. Similarly, there are Cognitive, memory, and compensation strategies (For a more comprehensive introduction of these strategies, see Oxford, 1990).

The use of such strategies while learning collocations makes language learning more efficient and leads to positive effects on learners' language (O'Mally \& Chamot, 1990; Oxford, 1996; Wenden \& Rubin, 1987). Within the same line of research, raising awareness of collocations for students is necessary as Herbst (1996) stated "competence in a language involves knowledge about collocations" (p. 389), and a reading course is a means by which teachers can help students learn collocations much more efficiently. One common problem EFL/ESL learners encounter is that they have difficulties with reading comprehension; therefore, providing them with concrete strategies for approaching reading tasks is necessary (Malena \& Atwood-Coker, 1987).

Research has also demonstrated that explicit instruction of reading strategies can improve the reading comprehension skills of students, and students lacking these skills who receive such instruction often become indistinguishable from more skilled readers (Dowhower, 1999). Research has indicated that skilled and less so skilled readers employ quite different strategies while dealing with a particular text. While the former prefer strategies such as paraphrasing and making the information more individual, the latter do not seem to resort to any special strategies, except underlining and repeated reading (Dowhower, 1999). 
Both research and classroom observation have shown that many language learners find it difficult to use collocations correctly and appropriately and previous studies have indicated that even advanced EFL learners have some common problems with collocations (e.g., Farghal \& Obiedat, 1995).

It has generally been found that in many reading classes even in situations where teachers devote much time teaching collocations and students spend plenty of time learning their meaning and practicing them through different tasks and activities, results have been disappointing, and still students have a lot of problems to recall, relate, and use collocations they have learned.

Although language learning strategies, as a part of the language learning process, have received much attention in the late 1970s in different areas of EFL learning in Iran, few studies have considered the use of strategies for learning collocations among Iranian EFL and ESP learners in reading classes. This study was intended to investigate different strategies used by Iranian EFL learners to learn collocations while reading English texts. The purpose of the study is to look for empirical support exploring different strategies used by EFL and ESP learners in order to learn collocations and to find out whether there is any difference between performance of EFL and ESP learners in learning collocations through reading. If learners know these strategies, they will be more active in the language learning process making them more efficient and positive in their approach to learning (Hedge, 1993), and finally, the knowledge of learning strategies has an effect on learners' motivation, self-efficacy, autonomy, and language proficiency which results in the ultimate aim of language learning.

Based on the above-mentioned considerations the following research questions are formulated:

1-What language learning strategies are used by Iranian intermediate EFL learners while dealing with collocations in reading classes?

2- What language learning strategies are used by Iranian intermediate ESP learners while dealing with collocations in reading classes?

\section{METHODOLOGY}

\section{A. Participants}

Iranian EFL and ESP learners were the population of the study. In order to choose the participants, two groups were formed. The EFL participants were 182 intermediate EFL undergraduate students, consisting of 65 males and 117 females, majoring in Translation and TEFL. These participants were selected from a sample of 250 EFL learners based on the Solution Placement Test (Edwards, 2007). The ESP participants were 146 undergraduate students (selected from a larger sample of 185 ESP learners after taking the placement test) majoring in Electronics, Nursing, and Medicine. Of these participants, 58 were male and 88 were female. All the participants were from IAU-Najafabad Branch, University of Isfahan, and IAU-Khorasgan Branch.

To ensure the homogeneity of the EFL and ESP groups, an independent samples t-test was conducted. The results of the t-test comparing the EFL group $(M=36.10, S D=1.71)$ and ESP group $(M=36.14, S D=1.64)$ showed no significant difference in proficiency, $t_{(326)}=.25, p=.84$.

\section{B. Instrumentation}

The instruments employed in this study were Solution Placement Test, a Collocation Test, and Strategy Inventory of Language Learning (SILL) (Oxford, 1990).

First, to make sure that the ESP and EFL participants of the study were homogeneous in terms of language proficiency, Solution Placement Test was used. The test has three independent parts: 50 multiple-choice tests targeting grammar and knowledge of vocabulary, 10 items checking participants reading comprehension, and a writing task.

McCarthy and O'Dell's (2007) and Marks and Wooder's (2007) were the main sources of the test, consisting 15 multiple-choice items following reading passages. Considering the fact that the test was researcher made, it was imperative that the reliability and validity of the test be checked. To do so, it was first piloted on a sample of EFL/ESP learners who were similar to the participants of the study, especially in terms of foreign language proficiency. The results of the pilot study were subjected to KR-21, which indicated that the test had a relatively high internal consistency $(\mathrm{r}=0.79)$.

In addition to being reliable, it was critical for the test to be valid too. Therefore, the test was given to three experts in the field. This was done because as Chapelle (1994) pointed out "construct validity is central to all facets of validity inquiry, as most researchers have agreed for some time" (p. 161). Based on the experts' feedback, some minor changes were made.

Strategy Inventory of Language Learning (SILL) is the version of the test used for speakers of other languages learning English (Oxford, 1990). It consists of 50 close-ended questions with a five-point Likert scale, ranging from 1 to 5. In fact, the participants read the items, and then give a scale of 1 to 5 based on the instruction given.

\section{Procedure}

After choosing the participants and placing them in relevant groups, EFL and ESP intermediate learners in each group took the collocation test. In this section, they were asked to read a passage, containing different collocations, and 
then they were instructed to complete the test. After that, the questionnaire (SILL) was given to the participants and they were asked to remember the strategies they have used while learning collocations in reading.

\section{RESUlts}

\section{A. EFL Questionnaire}

PCA was run to analyze the fifty items of 'the strategy inventory for language learning' (SILL). In order to be sure if PCA or Factor Analysis must be run, data's suitability must be confirmed. The results showed that the correlation matrix enjoyed plenty of coefficients which were at least .30. Similarly, to ensure the factorability, KMO was run, which was .69 (more than the suggested value of .60 put forward by Kaiser, 1970; 1974). For a similar purpose, the results indicated statistical significance for Bartlett's Test of Sphericity, as suggested by Bartlett (1954). The results of the analysis can be seen in Table 1 which presents the results of KMO and Bartlett's Test for EFL participants.

TABLE 1.

RESULTS OF KMO AND BARTLETT'S FOR EFL PARTICIPANTS

\begin{tabular}{lll}
\hline Kaiser-Meyer-Olkin Measure of Sampling Adequacy. & .69 \\
Bartlett's Test of Sphericity & Approx. Chi-Square & 4.84 \\
& Df & 1225 \\
& Sig. & .000 \\
\hline
\end{tabular}

The results of PCA or Factor Analysis revealed the presence of five components (factors), which is to a great extent compatible with Oxford's (1989) six categories of language learning strategies. The results indicate five components, with eigenvalues exceeding 1 , constitute $19.755 \%, 6.437 \%, 5.707 \%, 4.665 \%$, and $4.538 \%$ of the variance, respectively.

Table 2 shows the results of factor analysis, 'Rotated Component Matrix' for EFL participants, for 50 items in the questionnaire. As mentioned above, the results from the questionnaire yielded five factors. 
TABLE 2.

ROTATED COMPONENT MATRIX FOR EFL PARTICIPANTS

\begin{tabular}{lcc}
\hline & Component & 2 \\
& 3 & .479 \\
\hline 38. I think about my progress in learning SL. & .686 & .647 \\
37. I have clear goals for improving my SL skills. & .624 \\
31. I pay attention to my lapses and benefit from them to perform better. & .549 \\
32. I try to notice as others are speaking SL. & .532 \\
33. I do my best to become a better SL learner. & .476 \\
12. I practice the sounds of SL. & .471 \\
30. I try to find as many ways as I can to use my SL. & .449 \\
36. I look for opportunities to read as much as possible in SL. & .428 \\
22. I try not to translate word for word. & .410 \\
17. I write notes, messages, letters, or reports in the SL. & .393 \\
20. I try to find patterns in the SL. & .333 \\
24. To understand unfamiliar SL words, I make guesses. & \\
10. I say or write new SL words several times. &
\end{tabular}

27. I read SL without looking up every new word.

47. I practice SL with other students.

3. I try to remember the word by making connection between the sound of new words and a mental picture. .612

48. I ask for help from SL speakers. $\quad .610$

14. I start conversations in the SL.

40. I encourage myself to speak SL even when I am afraid of making a mistake.

39. I try to relax whenever I feel afraid of using SL.

44. I talk to someone else about how I feel when I am learning SL. 496

11. I try to talk like native SL speakers. $\quad .494$

49. I ask questions in SL.

5. I use rhymes to remember new SL words.

50. I try to learn about the culture of SL speakers.

6. I use flashcards to remember new SL words. 628

28. I try to guess what the other person will say next in the SL.

21. I try to figure the meaning of SL words breaking them into parts.

15. I watch SL language TV shows spoken in SL or go to movies spoken in SL.

35. I look for people I can talk to in SL.

2. I use new SL words in a sentence so I can remember them.

34. I plan my schedule so I will have enough time to study SL. .495

41. I give myself a reward or treat when I do well in SL.

25. When I can't think of a word during a conversation in the SL, I use gestures.

16. I read for pleasure in the SL. 306

23. I make summaries of information that I hear or read in the SL. .562

29. I try to use a similar word, if I can't find an SL word.

18. I first skim an SL passage (read over the passage quickly) then go back and read carefully.

1. I make relationships between things I know and the ones I learn. 496

9. I try not to forget new words by remembering their locations. .480

26. I make up new words if I do not know the right ones in the SL. .468

8. I review SL lessons often. $\quad .461$

13. I use the SL words I know in different ways.

42. I notice if I am tense or nervous when I am studying or using SL.

19. I look for words in my own language that are similar to new words in the SL.

4. I never forget a new word if I make an image of the place where it is used. .613

46. I ask SL speakers to correct me when I talk.

45. If I do not get a point in SL, I ask the interlocutors to repeat themselves.

43. I keep a diary of my feelings. $\quad .477$

7. I physically act out new SL words.

B. EFL Learners' Use of Language Learning Strategies 
The first research question of the study was intended to explore what language learning strategies Iranian intermediate EFL learners use in reading classes while dealing with collocations. It is essential to reiterate that the results of PCA revealed five components or factors. Factor 1, the largest component of language learning motivation for the EFL sample, $19.755 \%$ of all the items' variance, has a heavy loading from 13 statements $(38,37,31,32,33,12,30$, 36, 22, 17, 20, 24, and 10), such as 'I think about my progress in learning SL,' 'I have clear goals for improving my SL skills', 'I pay attention to my lapses and benefit from them to perform better', 'I try to notice as others are speaking SL', and 'I do my best to become a better SL learner'. These items along with some other statements presented in Table 2 refer to underlying psychological conditions for learning which are characterized in Oxford's (1989) 'Metacognitive' strategy category. Therefore, Factor 1 was named 'Metacognitive'.

In addition, the table presents the other factors as well. Factor 2, with $6.437 \%$ of all the items' variance, has a loading from 11 statements $(47,3,48,14,40,39,44,11,49,5$, and 50), such as 'I practice SL with other students', 'I ask for help from SL speakers', 'I ask questions in SL' which mainly correspond to Oxford's Social strategy, and 'I encourage myself to speak SL even when I am afraid of making a mistake', 'I try to relax whenever I feel afraid of using SL', and 'I talk to someone else about how I feel when I am learning SL' which are related to Oxford's Affective strategy. Therefore, it can be said that the second factor, Factor 2, for the EFL participants of the study can be labeled 'SocialAffective'.

Factor 3, with $5.707 \%$ of all the items' variance, receives a loading from 10 statements $(6,28,21,15,35,2,34,41$, 25 , and 16), such as 'I find the meaning of an SL word by dividing it into parts that I understand', 'I find the meaning of an SL word by dividing it into parts that I understand', and 'I read for pleasure in the SL', which match Oxford's Cognitive strategy, and 'I try to predict what my interlocutors will say next' and 'When I can't find a suitable word during a conversation in the SL, I use gestures' which correspond with Oxford's Compensatory strategy. Consequently, Factor 3 can be named 'Cognitive-Compensatory'.

Similarly, Factor 4, with $4.665 \%$ of all the items' variance, receives a loading from 9 statements $(23,29,18,1,9,26$, 8, 13, and 42), such as 'I make a short summary of what I face in the SL', 'I first skim the passage then read it carefully', and 'I use the SL words I know in different ways', which again refer to Oxford's Cognitive strategy, and 'I make relationships between things I know and the ones I learn', 'I try not to forget new words by remembering their locations', and 'I review SL lessons often', which are Oxford's Memory strategy. Therefore, it can be mentioned that Factor 4 can be labeled 'Cognitive-Memory'.

Finally, Factor 5, with $4.538 \%$ of all the items' variance, receives a loading from 5 statements $(4,46,45,43$, and 7), such as 'I try not to forget new words by remembering their locations', which come from Oxford's Memory strategy, and 'I expect correction from SL speakers when I am talking' and 'If I do not get a point in SL, I ask the interlocutors to repeat themselves' which come from Oxford's Social strategy. Thus Factor 5 can be called 'Memory-Social'.

In sum, as the results of Principal Component Analysis show, the Iranian EFL learners use five sets of strategies when dealing with collocations in reading passages, namely Metacognitive, Social-Affective, Cognitive-Compensatory, Cognitive-Memory, and Memory-Social.

\section{ESP Questionnaire}

PCA was run to analyze the fifty items of 'the strategy inventory for language learning' (SILL). In order to be sure if PCA or Factor Analysis must be run, data's suitability must be confirmed. The results showed that the correlation matrix enjoyed plenty of coefficients which were at least .30. Similarly, to ensure the factorability, KMO was run, which was .70 (more than the suggested value of .60 put forward by Kaiser, 1970; 1974). For a similar purpose, the results indicated statistical significance for Bartlett's Test of Sphericity, as suggested by Bartlett (1954). The results of the analysis for the ESP participants can be seen in Table 3.

TABLE 3.

RESULTS OF KMO AND BARTLETT'S FOR ESP PARTICIPANTS

\begin{tabular}{lll}
\hline Kaiser-Meyer-Olkin Measure of Sampling Adequacy. & .7 \\
\hline Bartlett's Test of Sphericity & Approx. Chi-Square & 4.99 \\
& Df & 1225 \\
& Sig. & .000 \\
\hline
\end{tabular}

Similar to the results of EFL participants, Principal Component Analysis revealed the existence of five components (factors) for ESP participants. Results indicate five components, with eigenvalues exceeding 1, explain 14.987\%, $6.815 \%, 6.233 \%, 5.476 \%$, and $4.584 \%$ of the variance, respectively.

Table 4 shows the results of factor analysis, rotated component matrix for ESP participants, for 50 items in the ESP questionnaire. As mentioned above, the results from the questionnaire yielded five factors. 
TABLE 4.

ROTATED COMPONENT MATRIX FOR EFL PARTICIPANTS

\begin{tabular}{|c|c|c|c|c|c|}
\hline & \multicolumn{5}{|c|}{ Component } \\
\hline & 1 & 2 & 3 & 4 & 5 \\
\hline 36. I look for opportunities to read as much as possible in SL. & .661 & & & & \\
\hline 11. I try to talk like native SL speakers. & .644 & & & & \\
\hline 14. I start conversations in the SL. & .630 & & & & \\
\hline 17. I write notes, messages, letters, or reports in the SL. & .621 & & & & \\
\hline 30. I try to find as many ways as I can to use my SL. & .558 & & & & \\
\hline 16. I read for pleasure in the SL. & .541 & & & & \\
\hline 49. I ask questions in SL. & .488 & & & & \\
\hline 40. I encourage myself to speak SL even when I am afraid of making a mistake. & .484 & & & & \\
\hline 15. I watch SL language TV shows spoken in SL or go to movies spoken in SL. & .467 & & & & \\
\hline 12. I practice the sounds of SL. & .441 & & & & \\
\hline 13. I try to employ SL words in a variety of ways. & .390 & & & & \\
\hline 2. I try to contextualize new words so than I remember them. & .351 & & & & \\
\hline 21. I try to figure the meaning of SL words breaking them into parts. & & .682 & & & \\
\hline 20. I find patterns in the SL. & & 610 & & & \\
\hline 26. I make up new words if I do not know the right ones in the SL. & & .578 & & & \\
\hline 48. I ask for help from SL speakers. & & .543 & & & \\
\hline 25. When I don't remember a word talking in the SL, I try to use gestures. & & .542 & & & \\
\hline 27 . When reading, I don't check every word in a dictionary. & & .485 & & & \\
\hline 45. If I do not get a point in SL, I ask the interlocutors to repeat themselves. & & .438 & & & \\
\hline 1. I think of relationships between what I already know and new things I learn in the SL. & & .436 & & & \\
\hline 35. I look for people I can talk to in SL. & & .434 & & & \\
\hline 32. I pay attention when someone is speaking SL. & & & .710 & & \\
\hline 24. To understand unfamiliar SL words, I make guesses. & & & .634 & & \\
\hline 22. I try not to translate word for word. & & & .564 & & \\
\hline 33. I try to find out how to be a better learner of SL. & & & .519 & & \\
\hline 50. I try to learn about the culture of SL speakers. & & & .518 & & \\
\hline 7. I physically act out new SL words. & & & .423 & & \\
\hline 42. I notice if I am tense or nervous when I am studying or using SL. & & & .420 & & \\
\hline $\begin{array}{l}\text { 3. I try to remember the word by making connection between the sound of new words and a mental } \\
\text { picture. }\end{array}$ & & & .352 & & \\
\hline 23. I make a short summary of what I face in the SL. & & & .300 & & \\
\hline 5. I use rhymes to remember new SL words. & & & & .615 & \\
\hline 43. I keep a diary of my feelings. & & & & .549 & \\
\hline 44. I try to communicate about my feelings when learning SL. & & & & .522 & \\
\hline 31. I notice my SL mistakes and use that information to help me do better. & & & & .478 & \\
\hline 47. I practice SL with other students. & & & & .469 & \\
\hline 6. I use flashcards to remember new SL words. & & & & .447 & \\
\hline 28. I try to guess what the other person will say next in the SL. & & & & .400 & \\
\hline 37. I have clear goals for improving my SL skills. & & & & .396 & \\
\hline 19. I look for words in my own language that are similar to new words in the SL. & & & & .370 & \\
\hline 38. I think about my progress in learning SL. & & & & .309 & \\
\hline 39. I try to relax whenever I feel afraid of using SL. & & & & & .628 \\
\hline 8. I review SL lessons often. & & & & & .612 \\
\hline 29. I try to use a similar word, if I can't find an SL word. & & & & & .599 \\
\hline 34. I plan my schedule so I will have enough time to study SL. & & & & & .559 \\
\hline 9. I try not to forget new words by remembering their locations. & & & & & .521 \\
\hline 46. I ask SL speakers to correct me when I talk. & & & & & .449 \\
\hline 41. I give myself a reward or treat when I do well in SL. & & & & & .385 \\
\hline 18. I first skim an SL passage (read over the passage quickly) then go back and read carefully. & & & & & .356 \\
\hline 4. I never forget a new word if I make an image of the place where it is used. & & & & & .334 \\
\hline 10. I say or write new SL words several times. & & & & & .330 \\
\hline
\end{tabular}

D. ESP Learners' Use of Language Learning Strategies 
Similarly, the second research question was aimed to investigate the types of language learning strategies Iranian intermediate ESP learners use in reading classes while dealing with collocations. Like the results of PCA for EFL participants, the results revealed the presence of five components or factors. Actually, Factor 1, the largest component of language learning motivation for the ESP sample, $14.987 \%$ of all the items' variance, has a heavy loading from 12 statements $(36,11,14,17,30,16,49,40,15,12,13$, and 2), such as 'I try to talk like native SL speakers,' 'I start conversations in the SL', 'I write notes, messages, letters, or reports in the SL', 'I read for pleasure in the SL', and 'I watch SL language TV shows spoken in SL or go to movies spoken in SL'. These items along with some other statements presented in Table 4 refer to underlying psychological conditions for learning which are characterized in Oxford's (1989) 'Cognitive' strategy category. Therefore, Factor 1 was named 'Cognitive'.

In addition, the table presents the other factors as well. Factor 2, with $6.815 \%$ of all the items' variance, has a loading from 9 statements $(21,20,26,48,25,27,45,1$, and 35), such as 'I make up new words if I do not know the right ones in the SL', 'When I don't remember a word talking in the SL, I try to use gestures', and 'When reading, I don't check every word in a dictionary' which mainly correspond to Oxford's Compensatory strategy, and 'I ask native speakers to help $m e$ ' and 'If I do not get a point in SL, I ask the interlocutors to repeat themselves', which are related to Oxford's Social strategy. Therefore, it can be said that the second factor, Factor 2, for the EFL participants of the study can be labeled 'Compensatory-Social'.

Factor 3, with $6.233 \%$ of all the items' variance, receives a loading from 9 statements $(24,22,33,50,7,42,3$, and 23), such as 'I try to notice as others are speaking SL' and 'I do my best to become a better SL learner', which match Oxford's Metacognitive strategy, and 'I try to remember the word by making connection between the sound of new words and a mental picture' which corresponds with Oxford's Memory strategy. Consequently, Factor 3 can be named 'Metacognitive-Memory'.

Similarly, Factor 4, with $5.476 \%$ of all the items' variance, receives a loading from 10 statements $(5,43,44,31,47,6$, $28,37,19$, and 38), such as 'I use rhymes to remember new SL words', 'I use flashcards to remember new SL words', and 'I look for words in my own language that are similar to new words in the SL', which again refer to Oxford's Cognitive strategy, and 'I notice my SL mistakes and use that information to help me do better', 'I have clear goals for improving my SL skills', and 'I think about my progress in learning SL', which are Oxford's Metacognitive strategy. Therefore, it can be mentioned that Factor 4 can be labeled 'Cognitive-Metacognitive'.

Finally, Factor 5, with 4.584\% of all the items' variance, receives a loading from 10 statements $(39,8,29,34,9,46$, 41, 18, 4, and 10), such as 'I frequently go over SL lessons' and 'I try not to forget new words by remembering their locations', which come from Oxford's Cognitive strategy, and 'I relax when I am scared of using SL' and 'I reward or treat myself when I successfully use SL' which come from Oxford's Affective strategy. Thus Factor 5 can be called 'Cognitive -Affective'.

In sum, as the results of Principal Component Analysis show, the Iranian ESP learner participants of the study used five sets of strategies when dealing with collocations in reading passages, namely Cognitive, Compensatory-Social, Metacognitive Memory, Cognitive-Metacognitive, and Cognitive-Affective. As can be seen from the results, ESP participants used cognitive strategies more than any other strategy.

\section{CONCLUSION}

The results can be compared with several similar studies. It seems necessary to mention that, originally, using factor analysis, Oxford (1989) categorized the SILL strategy groups. Oxford's attempts resulted in six factors or components, which were intended to have enough items to make a thorough understanding of learning strategies much easier for ESL/EFL learners. These strategies included Memory, Cognitive, Compensation, Metacognitive, Affective (emotional, motivation-related), Social strategies.

As can be seen from the results and discussion presented above, cognitive strategies form the largest category. The reason is that research has indicated that such strategies are quite versatile because of having greatest diversity. As Oxford and Ehrman (1995) pointed out this strategy contributes to a deep processing in which when learners are faced with new information, they try to analyze or synthesize it.

Another study which employed a similar factor analysis was Mochizuki (1999) who examined the kinds of strategies Japanese university students used as well as the kinds of factors that affect the learner's choice of strategies. Studying the Second Grade Test of the Society of Testing English Proficiency (STEP), he concluded that Japanese university students used compensation strategies the most often and affective ones the least. In addition, he found that more proficient participants used cognitive and metacognitive strategies more frequently than less proficient ones.

In a similar study, Kato (2005) concluded that as long as using and benefitting from strategies were concerned, his participants were average strategy users. As long as the distinction between the two genders is concerned Kato found that compensation strategies were more popular for girl students, while boys tended to resort to social ones. Using Factor Analysis, Kato presented five factors for Japanese university students, namely Metacognitive-Affective Strategies (Factor 1), Memory-Compensation Strategies (Factor 2), Social Strategies (Factor 3), Cognitive Strategies (Factor 4), and Entrance-Exam-Measured Strategies (Factor 5).

More recently, however, Al-Jabali (2012) investigated the level of use of foreign language learning strategies, examining their development in terms of the study-semester and gender variables by 45 Jordanian undergraduate 
English Language Majors. His results indicated for all strategies college students majoring TEFL were high strategy users. They preferred Metacognitive strategies more than the other strategies. After metacognitive strategies Jordanian university students were high users of Social, Compensation, Affective, Cognitive, and Memory strategies. In addition, the study did not find any significant difference between male and female's preference of strategies.

The results of the study can have several pedagogical implications for language classes. First of all, teachers' familiarity with language learning strategies and the role they play in language learning can help them have a better understanding of the learning process. Therefore, it is imperative for teachers to become aware of such language learning strategies, which gives them a better insight of their job. In addition, the results show that language learning strategies can be implemented in various skills and subskills. Previous research has proved that these strategies result in better performance by language learners in different skills (listening, speaking, reading, and writing) and certain subskills, such as vocabulary and grammar. This study, with the special focus on the efficacy of language learning strategies on collocations has indicated that developing such strategies in language learners (both EFL and ESP learners) does result in better learning of language, in general, and developing reading abilities in particular.

Other studies can be conducted to examine the efficacy of language learning strategies on other skills and subskills. This study dealt with the effects of language learning strategies while EFL and ESP learners are using collocations in reading passages. The same strategies can be investigated with other skills and subskills, such as writing and speaking. As mentioned in the previous section, one of the limitations of the study was that it was not possible to ask the participants about their feelings and thoughts at the time of using or choosing the strategies. Having interviews with participants, using introspection, and think-aloud protocols can be ideal candidates for further research. Another interesting area of research can be strategy training (Cubukcu, 2007) in which teachers are made aware of learning strategies more explicitly. Finally, asking teachers about language learning strategies is yet another interesting topic for further investigation. It is obvious that teachers are expected to become familiar with different aspects of language learning and teaching. It is believed that language teachers must become familiar with language learning strategies which will improve their cognition.

\section{REFERENCES}

[1] Al-Jabali, M. (2012). Language learning strategy use and concept development among Jordanian undergraduate English language majors. International Journal of Educatio 4.1, 161-180.

[2] Bartlett, M. S. (1954). A note on the multiplying factors for various chi square approximations. Journal of the Royal Statistical Society 16, 296-298.

[3] Chapelle, C. (1994). Are C-tests valid measures for L2 strategy research? Second Language Research, 10 (2), $157-187$.

[4] Cubukcu, F. (2007). An investigation of reading strategies employed by trainee teachers. GEMA Online Journal of Language Studies 7.2, 95-110.

[5] Dowhower, S. L. (1999). Supporting a strategic stance in the classroom: A comprehension framework for helping teachers help students to be strategic. The Reading Teacher 52.7, 672-688.

[6] Edwards, L. (2007). Solutions placement test. Oxford: Oxford University Press.

[7] Farghal, M. \& H. Obiedat. (1995). Collocations: A neglected variable in EFL. IRAL. International Review of Applied Linguistics in Language Teaching 33.4, 315-331.

[8] Hedge, P. (1993). Key concepts in ELT: Learner training. ELT Journal Volume 47.1, 92-93.

[9] Herbst, T. (1996). What are collocations: Sandy beaches or false teeth? English Studies 77.4, 379-393.

[10] Hsu, M. Y. \& S. C. Huang (2004). Elementary school students' strategy use: On gender and personality differences. In English Teachers' Association, ROC, The proceedings of the $13^{\text {th }}$ international symposium on English teaching, (pp. 444-451). Taipei: The Crane Publishing Ltd.

[11] Kaiser, H. (1970). A second generation Little Jiffy. Psychometrika 35, 401-415.

[12] Kaiser, H. (1974). An index of factorial simplicity. Psychometrika 39, 31-36.

[13] Kato, S. (2005). How Language Learning Strategies affect English Proficiency in Japanese University Students. BunkyouGakuin Daigaku-Kiyou 7.1, 239-262.

[14] Lawson, M. J. \& D. Hogben. (1996). The vocabulary-learning strategies of Foreign-language students. Language Learning 46.1, 101-135.

[15] Malena, R. F., \& K. J. Atwood-Coker. (1987). Reading *O*prehension: The missing elements. Journal of Developmental Education 10.3, 24-25, 35.

[16] Marks, J. \& A. Wooder. (2007). Natural English collocations. London: A \& C Black Publishers.

[17] Mayer, R. E. (1996). Learning strategies for making sense out of expository text: The SOI model for guiding three cognitive processes in knowledge construction. Educational Psychology Review 8, 357-371.

[18] McCarthy, M. \& F. O’Dell. (2007). English collocations in use. Cambridge: Cambridge University Press.

[19] Mochizuki, A. (1999). Language learning strategies used by Japanese university students. A Journal of Language Teaching and Research, 30.2, 101-113.

[20] O'Malley, J. M. \& A. U. Chamot. (1990). Learning strategies in second language acquisition. Cambridge: Cambridge University Press.

[21] Oxford, R. L. (1989). Use of language learning strategies: A synthesis of studies with implications for strategy training. System $17.2,235-247$.

[22] Oxford, R. L. (1990). Language learning strategies: What every teacher should know. Boston: Heinle \& Heinle.

[23] Oxford, R. L. (1996). Language learning strategies around the world: Cross-cultural perspectives. Manoa: University of Hawaii Press. 
[24] Oxford, R. L. \& M. E. Ehrman. (1995). Adults' language learning strategies in an intensive foreign language program in the United States. System 23, 359-386.

[25] Rubin, J. (1975). What the "good language learner" can teach us. TESOL Quarterly 9.1, 41-51.

[26] Simpson, J. \& E. Weiner. (1873). Oxford English dictionary. Oxford: Oxford University Press.

[27] Wenden, A. L. \& J. Rubin. (eds). (1987). Learner strategies in language learning. London: Prentice Hall.

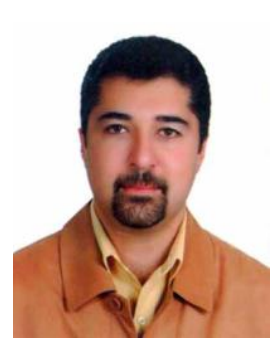

Omid Tabatabaei is an assistant professor at the English department of the Islamic Azad University, Najafabad Branch, Iran and currently the Head of the English Department in that university. His areas of interest are testing and assessment, research methodologies, psycholinguistics, language acquisition, and syllabus design. He has published and presented papers in international conferences and journals.

Hourieh-Sadat Hoseini is an MA graduate from Islamic Azad University-Najafabad Branch in Isfahan. Her research interests include language teaching and learning. She has been working as an English teacher for several years. She is currently teaching in Islamic Azad University-Najafabad Branch. 